\title{
The central case method in The Nature of Legislative Intent
}

\author{
Andrea Dolcetti ${ }^{1}$
}

In The Nature of Legislative Intent, Richard Ekins explores the nature of legislative intent and, in doing so, the nature of the legislature. ${ }^{2}$ More precisely, Ekins aims 'to perceive and explain the shape of the well-formed legislature'; and seeks to identify the central case of the legislature - that is to say, 'the form that the legislature has, if any, when it is chosen and maintained by practically reasonable persons'. ${ }^{3}$ To approach the nature of the legislature, Ekins employs the central case method. Although there are good reasons to employ this method (which I endorse), the book does not include a full explanation of the methodology that underpins its approach.

This article analyses the methodology that supports the identification of the central case of the legislature, with a view to discussing some aspects of Ekins' understanding of the nature of the legislature. My analysis also raises some questions that suggest new ways to engage with the arguments offered in Ekins' illuminating study of legislative intent; and future avenues for exploring the nature of the legislature, as an independent object of enquiry and/or as related to our understanding of the nature of law.

This article is organised in two parts, moving from the general to the particular. First, I illustrate John Finnis' version of the central case method, which is the main source of inspiration for Ekins' methodology. I begin with an explanation of the context in which Finnis has developed his methodology - i.e. the methodological debate in general jurisprudence $(\S 1.1)$. I, then, focus on three key elements of Finnis' methodology $(\S 1.2)$ : the reception of Aquinas' four orders of knowledge; the gnoseological priority of the 'Whyquestion' (over the 'What-question'); and the relationship between the central case and peripheral cases. In the second part of the article, I draw upon these elements to raise some

\footnotetext{
${ }^{1}$ This article is based upon a paper presented and discussed at a workshop on The Nature of Legislative Intent, which took place at Bocconi University (Milan) on 22-23 October 2018. I would like to thank all workshop participants and, in particular, Damiano Canale, Richard Ekins, Alessio Sardo, and Giovanni Tuzet. Special thanks to Daniela Simone and the anonymous reviewer for their constructive criticism and suggestions.

${ }^{2}$ Richard Ekins, The Nature of Legislative Intent (Oxford: Oxford University Press, 2012).

${ }^{3}$ Ibid, 9 and 118 - respectively.
} 
questions about three main aspects of Ekins' understanding of the nature of the legislature: the relationship between the well-formed legislature and the idea of a good polity ( $\$ 2.1)$; the notion that the well-formed legislature acts for good reasons (\$2.2); and the relationship between the well-formed legislature and the central case of law (§2.3).

\section{The background to Ekins' methodology}

Numerous aspects of The Nature of Legislative Intent suggest that Ekins' methodology has been inspired by the central case method theorised, and employed, by John Finnis to develop an explanatory definition of law. Ekins' language frequently echoes some of the expressions used by Finnis in his seminal book Natural Law and Natural Rights (now commonly associated with his methodology) - for example, 'practical reason(ing)'; '(un)reasonable persons'; 'goods valuable for all persons'; 'coordination towards the common good'; and 'central case'. Also, when discussing the best way to conceptualise and understand social reality, Ekins explicitly refers to Finnis' works. Two clear examples are provided by Ekins' treatment of group action and legislative action. In relation to group action, Ekins affirms that a group can be identified in light of the existence of a common purpose - including a reference to Finnis' book on Aquinas. ${ }^{4}$ When considering the relationship between the individual acts of the members of a group and that group's procedures, Ekins explicitly uses an example from Finnis' Natural Law and Natural Rights - that of a gate keeper in a factory. ${ }^{5}$ In relation to legislative action, Ekins affirms that the complex reasoning of the reasonable legislator should be understood in relation to all four orders of knowledge identified by Aquinas. ${ }^{6}$ Here again, Ekins points the reader in the direction of Finnis' reception of the philosophy of Saint Thomas Aquinas. ${ }^{7}$

Furthermore, at the beginning of Chapter 5 (entitled 'What It Is to Legislate'), Ekins affirms that 'the classical method of social theory is to adopt the perspective of the practically

\footnotetext{
${ }^{4}$ Ekins, The Nature of Legislative Intent, 52. In the footnote (n. 18), Ekins adds that 'Aquinas understood the acting group to be a unity of order in which acts of individual persons are unified by (i) their coordination and (ii) the point or purpose of that coordination'. Here, Ekins refers to John Finnis, Aquinas: Moral, Political, and Legal Theory (Oxford: Oxford University Press, 1998), 24-5.

${ }^{5}$ See John Finnis, Natural Law and Natural Rights, $2^{\text {nd }}$ ed. (Oxford: Oxford University Press, 2011), 151-2; and Ekins, The Nature of Legislative Intent, 60-1.

${ }^{6}$ Ekins, The Nature of Legislative Intent, 130: 'Aquinas identified four orders of knowledge: knowledge of the nature of things (centrally, of empirical facts), logic, moral evaluation, and technical craft'.

${ }^{7}$ See ibid, footnote n. 20. The reference is to John Finnis, Aquinas: Moral, Political, and Legal Theory, 21-2.
} 
reasonable person to identify the ends, or objects, of fully reasonable human action and thence to understand more or less confused or in other ways rationally defective purposes, actions, and institutions'. ${ }^{8}$ This sentence is followed by a footnote which includes references to pages 40-51 of Aquinas, and to Chapter 1 of Natural Law and Natural Rights. ${ }^{9}$ The latter reference is particularly interesting, given that it is precisely in that Chapter that Finnis explains his version of the central case method. ${ }^{10}$ Thus, it can be fairly said that The Nature of Legislative Intent is informed by the method theorised, and employed, in Natural Law and Natural Rights. ${ }^{11}$ The significance of Finnis' central case method must be properly appreciated in the context of $20^{\text {th }}$ Century analytical jurisprudence, and in relation to the scholarly debate on the best methodology for a general theory of law. I will, therefore, expound the theoretical background to Ekins' methodology starting with a brief recollection of the so-called 'methodology problem in jurisprudence' $(\$ 1.1)$. Subsequently, I will focus on three key elements of Finnis' methodology $(§ 1.2)$ - i.e. the reception of Aquinas' four orders of knowledge ( $\$ 1.2 .1)$; the gnoseological priority of the 'Why question' (over the 'What question’) (§1.2.2); and the relationship between the central case and the peripheral cases $(\S 1.2 .3)$.

\subsection{The methodology problem in jurisprudence}

Brian Leiter's 2003 article in The American Journal of Jurisprudence provides a good entry point to the contemporary debate about methodology and legal theory - a debate aptly captured by the expression 'the methodology problem in jurisprudence'. ${ }^{12}$ In this article, Leiter argues that the significant issues faced by legal positivists at the beginning of the $21^{\text {st }}$ Century are different, in kind, from the issues that Dworkin made famous in the Seventies and Eighties. These new issues, according to Leiter, can be grouped into two broad categories: 'the correct account of the content of the rule of recognition and its relationship to

\footnotetext{
${ }^{8}$ Ekins, The Nature of Legislative Intent, 118.

${ }^{9}$ Ibid, 118, footnote n. 2.

${ }^{10}$ Finnis' version of the central case method is linked to the so-called New Classical Natural Law Theory. See: John Finnis, Germain Grisez, and Joseph Boyle, "Practical Principles, Moral Truth, and Ultimate Ends", The American Journal of Jurisprudence 32 (1987): 99-151. See, also: John Finnis, 'Natural Law Theories', The Stanford Encyclopedia of Philosophy (Winter 2016 Edition), Edward N. Zalta (ed.), URL = <https://plato.stanford.edu/archives/win2016/entries/natural-law-theories/>.

${ }^{11}$ See, in particular, Finnis, Natural Law and Natural Rights, Chapters I and X.

12 Brian Leiter, "Beyond the Hart/Dworkin debate: the methodology problem in jurisprudence", The American Journal of Jurisprudence 48 (2003): 17-51. This article has been subsequently reprinted in B. Leiter, Naturalizing Jurisprudence, (Oxford: Oxford University Press, 2007), Chapter 6.
} 
the possibility of law's authority' (what Leiter calls 'the Hart/Raz debate'); and 'the proper methodology of jurisprudence'. ${ }^{13}$ According to Leiter, the scholarly debate on the best methodology for a general theory of law is more significant than the Hart/Raz debate, because 'it promises to show that there is a relevant sense in which law and morality are not separable by challenging the methodological presuppositions of legal positivists' ${ }^{14}$ It is worth noting that, despite his defence of a very different methodological approach, Leiter explicitly recognises the crucial role played by Finnis' scholarship in the contemporary debate about methodology and legal theory. ${ }^{15}$ In particular, Leiter acknowledges that this debate has been shaped by an appreciation of Finnis' methodological proposal. ${ }^{16}$

Chapter 1 of Finnis' Natural Law and Natural Rights defends and develops a method that improves - and, in a sense, challenges - the methodological approach endorsed by H.L.A. Hart's The Concept of Law. ${ }^{17}$ Hart explicitly saw his book as a work both in analytical jurisprudence and in descriptive sociology. ${ }^{18}$ Because of this dual characterisation, the method embraced by Hart in The Concept of Law can be seen as 'one of conceptual analysis, the aim of which is to describe the features in virtue of which some phenomenon should be classified as "law". ${ }^{19}$ Hart employs this method to answer the question 'what is law?' - an issue that has been and, to a certain extent, remains central to general jurisprudence. Indeed, influential legal philosophers such as John Austin and Hans Kelsen have grappled with the same issue. Hart's theory retains Austin and Kelsen's identification of the object of

${ }^{13}$ B. Leiter, "Beyond the Hart/Dworkin debate: the methodology problem in jurisprudence", 18.

${ }^{14}$ B. Leiter, "Beyond the Hart/Dworkin debate: the methodology problem in jurisprudence", The American Journal of Jurisprudence 48 (2003): 18. According to Leiter, the Hart/Raz debate 'is intramural, taking place against a background of some shared positivist assumptions'.

${ }^{15}$ For an historical overview of the methodology that informs Leiter's 'naturalistic project', see: Leiter, Naturalizing Jurisprudence, "Introduction".

${ }^{16}$ Finnis' methodology has received much attention amongst legal philosophers. In his 2003 AJJ article, Leiter recalls: Stephen R. Perry, 'Hart's Methodological Positivism', in Jules Coleman (ed.), Hart's Postscript: Essays on the Postscript to the Concept of Law, (Oxford: Oxford University Press, 2001); and Julie Dickson, Evaluation and Legal Theory, (Oxford: Hart Publishing, 2001).

${ }^{17}$ For a discussion of Finnis' methodology, seen as an objection to Hart's 'descriptive' jurisprudence, see: Alex Langlinais and Brian Leiter, 'The Methodology of Legal Philosophy', in Herman Cappelen, Tamar Szabó Gendler, and John Hawthorne (eds.), The Oxford Handbook of Philosophical Methodology, (Oxford: Oxford University Press, 2016).

${ }^{18}$ See H.L.A. Hart, The Concept of Law, $3^{\text {rd }}$ ed. (Oxford: Oxford University Press, 2012), vi: 'The lawyer will regard the book as an essay in analytical jurisprudence, for it is concerned with the clarification of the general framework of legal thought, rather than with the criticism of law or legal policy. [...] Notwithstanding its concern with analysis the book may also be regarded as an essay in descriptive sociology'.

${ }^{19}$ Nicholas McBride and Sandy Steel, Great Debated in Jurisprudence (London: Palgrave, 2014), 15. Emphasis in the original. 
jurisprudence as positive, human-made, law. There is, however, an important methodological difference between Hart's conceptual analysis and the theories of Austin and Kelsen. Hart's project aims to identify and explain certain features that make something 'law', but this is not seen as requiring the identification and the explanation of a set of necessary and sufficient conditions that would allow one to distinguish the phenomena called 'law' from the phenomena classified as 'not-law'. ${ }^{20}$ Instead, in order to understand the nature of law, Hart focuses on 'standard', or 'central', cases of law: most importantly, the legal systems that we recognise as 'municipal law'. ${ }^{21}$ Hart links his method to a descriptive theory of law, in which evaluation might be part of the object of study, but not of the theory itself. ${ }^{22}$ Finnis challenges this view, by arguing that evaluation is part of the object of study (in this case, legal phenomena) as well as of the theories that describe and explain that object (in this case, general theories of law). This is because general descriptive theorists must choose, in the myriad of phenomena connected with the reality that we call 'law', what is salient for the purposes of descriptive legal theory - and this choice amounts to an evaluation. Despite its methodological significance, the importance of value-judgments for the purposes of a descriptive theory of law is not the defining aspect of Finnis' methodology. The characteristic feature of Finnis' methodology lies in the kind of evaluation that general descriptive theorists should use to select the observed phenomena - i.e. how the theorists should identify what is salient for the purposes of a descriptive general theory of law.

Finnis acknowledges that Hart's and Raz's methodology have greater explanatory power than 'the rather naive methodologies of Bentham, Austin, and Kelsen'. ${ }^{23}$ The methodological

\footnotetext{
${ }^{20}$ See H.L.A. Hart, The Concept of Law, 199: 'We shall no longer have to choose between two unsuitable alternatives which are often taken as exhaustive: on the one hand, that of saying that this is required by "the" meaning of the words "law" or "legal system", and on the other, that of saying that it is "just a fact" that most legal systems do provide for sanctions. Neither of these alternatives is satisfactory. There are no settled principles forbidding the use of the word "law" of systems where there are no centrally organized sanctions, and there is good reason (though no compulsion) for using the expression "international law" of a system, which has none'.

${ }^{21}$ Ibid, 3: '...besides the clear standard cases constituted by the legal systems of modern states, which no one in his senses doubts are legal systems...'. Ibid, 216: '...municipal law, which is taken as the clear, standard example of what law is'.

${ }^{22}$ In his response to Dworkin, Hart affirms that: '... even if the judges and lawyers of all the legal systems of which the general and descriptive legal theorist had to take account themselves did in fact settle questions of meaning in this interpretive and partly evaluative way, this would be something for the general descriptive theorist to record as a fact... [...] Description may still be description, even when what is described is an evaluation'. H.L.A. Hart, The Concept of Law, 244.

${ }^{23}$ According to Finnis, Bentham and Austin did not pay much attention to the problem of how theorists should decide what is to count as law for the purposes of their theories: they explained a number of legal phenomena in light of definitions simply posited at the start of their inquiries. And Kelsen, who was more interested in
} 
approaches developed by Hart and Raz owe their superiority to the following three features: attention to practical point; the selection of a central case and focal meaning; and the selection of a viewpoint. For the purposes of this article, the last feature is particularly important, because the distinctiveness of Finnis' methodology lies precisely in the way in which he understands the selection of the best viewpoint for a general theory of law. Finnis argues that: '[in] relation to law, the most important things for the theorist to know and describe are the things which, in the judgment of the theorist, make it important from a practical viewpoint to have law - the things which it is, therefore, important in practice to "see to" when ordering human affairs'. ${ }^{24}$

It should be noted that Finnis' central case method has been theorised and employed in relation to law, but it is part of a methodology that is valid for a number of disciplines interested in social reality and human affairs. Finnis explains that the challenge for a general theory in the social sciences 'is not to find or devise definitions which will extend to all circumstances in which, regardless of particular points of view, the word being defined could "correctly" be employed. ${ }^{25}$ One should, instead, look for, and establish, the focal meaning of theoretical concepts with the intention of developing an 'explanatory definition'. ${ }^{26}$ In order to do so, it is necessary to follow a method which aims at the explanation of 'the links between human institutions and the values and requirements of practical reasonableness. ${ }^{27}$

The upshot of Chapter 1 of Natural Law and Natural Rights can therefore be applied not only to general jurisprudence, but also to any other discipline and enquiry interested in social reality and human affairs: '...the methodological problems of concept-formation as we have traced it [in Chapter 1 of Natural Law and Natural Rights] compel us to recognize that the point of reflective equilibrium in descriptive social science is attainable only by one in whom wide knowledge of the data, and penetrating understanding of other persons' practical

methodology than Bentham and Austin, tried to find one or more features common to all the concrete instances of law (defined as a type of social technique).

${ }^{24}$ Finnis, Natural Law and Natural Rights, 16.

${ }^{25}$ Ibid, 265. Emphasis in the original. In relation to his definition of law - seen as a social reality that can be captured by a general concept - Finnis underlines that his purpose has not been to explain: 'an unfocused "ordinary concept" but to develop a concept for use in a theoretical explanation of a set of human actions, dispositions, interrelationships and conceptions'. Ibid, 278.

${ }^{26}$ See Finnis, Natural Law and Natural Rights, 265 and 278.

${ }^{27}$ Ibid, 265. More generally: '...the point of a jurisprudence such as is exemplified in this chapter is to explain certain human institutions by showing how they are responses to the requirements of practical reasonableness'. Ibid. 
viewpoints and concerns, are allied to a sound judgment about all aspects of genuine human flourishing and authentic practical reasonableness' ${ }^{28}$

\subsection{Three key elements of Finnis' methodology}

The purpose of this sub-section is to expand on three key elements of Finnis' methodology: the reception of Aquinas' four orders of knowledge; the gnoseological priority given to the 'Why-question' (over the 'What-question'); and the importance of the relationship between central and peripheral cases. In the second part of the article, these three elements will help me discuss three main aspects of Ekins' understanding of the nature of the legislature.

\subsubsection{Finnis' reception of Aquinas' four orders of knowledge}

A first, crucial, element of Finnis' central case method is the appreciation of different ways in which a set of phenomena can be conceptualised as a unity and, therefore, as a discrete object of inquiry. Here, Finnis follows Aquinas' identification of 'four basic ways in which human understanding stands to unifying relationships'. ${ }^{29}$ According to Finnis, there are four ways in which a given set of persons can be seen as forming a group (or a community). ${ }^{30}$ Providing an account of these four unifying relationships (or orders) is necessary so as not to lose sight of the complexity that characterises social reality. Otherwise, there a risk of focussing attention only on some aspects of social reality, and/or trying to explain one of the orders of that reality with conceptual apparatus that belongs to a different order.

The first order, studied by the so-called 'natural sciences', is the order that human beings cannot create, but that we can nonetheless understand. If one considers a human group - e.g. a family - it appears that the individual members of this group have physical and biological relationships that distinguish them, as a group, from other individuals as well as other groups. Continuing with this example, it would be correct to say that the members of a family form a

\footnotetext{
${ }^{28}$ Finnis, Natural Law and Natural Rights, 17-8.

${ }^{29}$ Ibid, 136. See, also, Finnis, Aquinas: Moral, Political, and Legal Theory, 20-3.

30 This key element of Finnis' methodology emerges when Finnis discusses different levels of reality in connection with the problem of when a given set of persons should be considered to be a group. To illustrate this point, Finnis uses the example of a gate keeper who opens and shuts a factory gate for incoming and outgoing lorries of independent contractors who bring supplies for the factory through that gate. See Finnis, Natural Law and Natural Rights, 151-52.
} 
group because of their shared genetic heritage. ${ }^{31}$ However, it is commonly accepted that there is more to a family than the mere genetic connections shared by a number of individuals. Another example used by Finnis is that of a group constituted by the people in a classroom, attending a lecture: in this case, it is possible to identify a unifying relationship that is brought about by the fact that the students perceive the sounds generated by the lecturer's vocal chords (including all the elements and pre-conditions of this physical interaction). Here, again, our experience of a lecture - as students and/or lecturers - tells us that the fact of spending time in the same room, producing and/or perceiving sounds is just one of the elements (and not the most important one) of a lecture. In other words, the physical interactions between the students and the lecturer captures only one sense in which they form a group.

The second order, studied by disciplines such as logic, epistemology, and methodology, is the order that human beings can bring into their own understanding. This type of order, or unifying relationship, manifests itself in the internal coherence of each body of knowledge. Referring back to the example of a family, it can be argued that 'a family can have a special unity in this order of relationships, inasmuch as its members think and learn together, acquiring a common fund of experience and insight, and even knowing how much the others know...? 32 This type of unifying relationship indicates another sense in which the members of a family can be seen to form a group, on top of their genetic unity (i.e. the first order considered in the previous paragraph). In the example of the lecture, when the students not only hear, but also listen to, the explanations and the arguments articulated by the lecturer, they end up sharing the same understanding of a given set of propositions with the lecturer. In doing so, the students and lecturer can be seen as constituting a group, the unity of which lies in the unity of their intellectual activities and, consequently, of their knowledge. This type of order, or unifying relationship, is of course compatible with the physical interactions in the classroom - however, this second order appears to make better sense of the claim that students and lecturer form a group.

The third order, studied by the arts and applied sciences, is the order that human beings create and impose upon a given (subject-) matter. The members of a family 'can have a special

\footnotetext{
${ }^{31}$ For the purposes of this paragraph, the fact that the genetic connections between family members are neither symmetrical nor bi-univocal is disregarded.

${ }^{32}$ Finnis, Natural Law and Natural Rights, 137.
} 
unity in this order of relationships, inasmuch as its members share not only house and property and possessions but also a range of especially subtle modes of communication with one another...' ${ }^{33}$ At a more general level, the members of a given human group have in common elements such as a shared language, common technology, the same capital stock: these elements form a type of unity that is different from the two orders considered above. Consider, once again, the lecture scenario: when the students are capable of decoding and comprehending the symbols and expressions used by the lecturer to convey meaning and transfer knowledge to them, then the individuals taking part in the lecture can be seen to form a group in a sense that complements the two unifying relationships identified in the previous two paragraphs.

The fourth order is the order that human beings create by intentionally acting on the basis of deliberation and choice. This type of order, or unifying relationship, is studied by disciplines such as psychology, history, and ethics. On top of the three orders considered in the previous paragraphs, 'a family can have a special unity in this order of relationships, inasmuch as each of its members (especially the one(s) directing and shaping the common life) is devoted to finding his or her own self-fulfilment (at least in part) in helping the other members to fulfil themselves, by caring for them and helping them to grow in freedom and responsibility and other basic aspects of human flourishing. ${ }^{34}$ The unity created by deliberate joint action even when the individual members of the group do not perform the same action - is a crucial element in identifying a given set of individuals as a group. Think about a sport team and the different actions performed by the individual players (including the reserve players). Returning to the lecture example, the strongest sense in which the students and the lecturer form a group is that they have deliberately chosen to act jointly in the transmission and sharing of knowledge. In this context, the communication and acquisition of knowledge are aspects of the same deliberate joint action (or plan).

When considering human affairs, the fourth order is the strongest form of unifying relationship; and the most important for theoretical purposes. It should be stressed that the four unifying relationships illustrated above are not mutually exclusive. To a certain extent, each 'superior' order includes the 'inferior' $\operatorname{order}(\mathrm{s})$ : for instance, deliberate joint action requires some pre-conditions that are captured by the other three unifying relationships. It

\footnotetext{
${ }^{33}$ Finnis, Natural Law and Natural Rights, 137.

${ }^{34}$ Ibid, 138.
} 
should also be noted that the type of unity created by deliberate joint action raises two crucial questions about the nature of human groups and communities: (1) How several individuals form a group (in the fourth order)?; and (2) Why several individuals form a group (in the fourth order)? Finnis' methodology not only answers this two questions, but also demonstrates that they are connected. First, individuals create a group (in the fourth order) by collaborating in pursuance of a deliberate joint action (or plan). This collaboration is realised by the co-ordination of the individual actions of each member of the group - consider, again, the members of a sport team. ${ }^{35}$ Secondly, human groups (in the fourth order) are characterised by their purpose, given that they are created by deliberate joint action, which is in turn defined and sustained by its purpose. This last point indicates the connection between Finnis' reception of Aquinas' four orders of knowledge and the gnoseological priority that the 'Why-question' enjoys in Finnis' methodology.

\subsubsection{The gnoseological priority of the 'Why-question'}

It is common opinion that one of the main tasks, if not the task, of analytical jurisprudence is to answer the question 'What is Law?' ${ }^{36}$ In 'Law and What I Truly Should Decide', Finnis develops a powerful argument to support the view that theoretical investigations about law including the enquiry about the nature of law (i.e. what the law is) - should begin with the following question: 'Why have the sort of thing or things that get called the law and legal system, legal institutions, and processes and arrangements that we call the law of our time and town?'37 According to Finnis, this question entails the question 'Why, if at all, should we have law? ${ }^{38}$ Finnis also explains that this question is asked in the context of an exercise of practical reasoning, when a person reflects and deliberate about what they should really do. Finnis embraces the methodology proper to Aristotle and the natural law tradition - which in the context of a general theory of law means that the identification of what law is depends upon an understanding of why law is a reasonable response to common human needs. ${ }^{39}$

\footnotetext{
${ }^{35}$ When Finnis talks of co-ordination, he also takes this idea to include 'negative co-ordination', i.e. mutual noninterference. See Finnis, Natural Law and Natural Rights, 138.

${ }^{36}$ Hart followed Bentham and Austin in firmly distinguishing 'law as it is' from 'law as it ought to be', identifying in the former the object of enquiry proper to jurisprudence. See, e.g.: H.L.A. Hart, "Positivism and the Separation of Law and Morals", Harvard Law Review 71 (1958): 593-629.

${ }^{37}$ John Finnis, "Law and What I Truly Should Decide", American Journal of Jurisprudence 48 (2003): 108.

38 Ibid, 108.

39 John Finnis, "Natural Law Theories", The Stanford Encyclopedia of Philosophy (Winter 2016 Edition), Edward N. Zalta (ed.), URL = <https://plato.stanford.edu/archives/win2016/entries/natural-law-theories/>.
} 
Before explaining the reason that gives gnoseological priority to the 'Why-question' over the 'What-question', I would like to highlight that Finnis' argument has been developed with special reference to general jurisprudence, but is also applicable to other theoretical disciplines interested in human affairs. ${ }^{40}$ According to Finnis, a good theory is more a matter of judgment than choice, in the sense that one's choice is limited to the possibility of pursuing the questions prompted by a particular subject-matter: therefore, it is more appropriate to say that one develops, rather than construct, a general theory of law, and/or other social phenomena. ${ }^{41}$

Instead of the question 'what is law?', one can think of the question 'what is an argument?'. If I say that I recognise an argument, I usually mean that I take a set of connected propositions as reasons for accepting a conclusion $\mathrm{C}$ that follows from those propositions. I could also recognise that other propositions, offered by another person to support C, do not in fact support C. For Finnis, in order to grasp what an argument is, it is necessary to understand why we have an argument in the first place - that is to say, answering the question: why are those propositions linked in a particular way (and not simply juxtaposed) to lead one to conclude that $\mathrm{C}$ is the case? Asking why we have an argument in relation to $\mathrm{C}$ gives one a standpoint from which it is possible to recognise that, although different arguments are offered in support of $\mathrm{C}$, some of these arguments fail qua arguments - at all, or in relation to C. Nonetheless, one should appreciate that '.. what argument really is consists in coming to understand that, and why, not all arguments are really arguments at all, even though these non-arguments - failed, fallacious, invalid arguments - are still, in a secondary or watered down sense, arguments, as eclipses and clocks and people and most of the other subject matters in this or any imaginable universe are simply not. ${ }^{42}$

\subsubsection{The relationship between the central case and the peripheral cases}

A third key element of Finnis' methodology is the attention to the central case of the social reality that the theorist is studying. Legal theorists should identify this central case in light of

\footnotetext{
${ }^{40}$ Finnis' view on the importance of the 'Why-question' has been recently revisited in Grégoire Webber, "Asking Why in the Study of Human Affairs", American Journal of Jurisprudence 60 (2015): 51-78.

${ }^{41}$ Finnis, "Law and What I Truly Should Decide", 125.

${ }^{42}$ Ibid, 108.
} 
the human needs that require reasonable persons to establish and maintain legal norms and legal institutions; and in light of the common good of the community those norms and institutions are meant to serve. Finnis' central case method is inspired by the methodology followed by Aristotle to identify central and peripheral cases of friendship. For the purposes of this article, it is important to underline that for Finnis '...there is no point in denying that the peripheral cases are instances (of friendship, constitutionality...). Indeed, the study of them is illuminated by thinking of them as watered-down versions of the central cases, or sometimes as exploitations of human attitudes shaped by reference to the central case. ${ }^{43}$ In light of this methodology, regimes like Hitler's Germany or Stalin's Russia can be identified and studied as peripheral cases of constitutional government. ${ }^{44}$

For Finnis, every central case should be described in a way that preserves its richness, capturing all aspects of the central case, including the aspects that may not be present in the peripheral cases. Central and peripheral case can be compared and studied in light of the features that they (do not) share. In this context, Finnis talks of ' ....network of similarities and differences, the analogies and disanalogies, for example, of form, function, or content, between [the peripheral cases] and the central cases. ${ }^{45}$ The key to exploring the relationship between the central case and the peripheral cases is the identification of the rationale which allows a given term (which is used in its focal meaning only when it refers to the central case) to extend from the central case to the peripheral and borderline cases. ${ }^{46}$

In the Postscript to the second edition of Natural Law and Natural Rights, Finnis argues that the centrality of a concept depends upon the viewpoint, as well as the purposes, of the person employing the central case method ${ }^{47}$ Finnis' methodology requires a theorist to develop a central case from a viewpoint identified in light of an account of certain basic human goods, and certain principles of practical reasonableness that direct our action towards those goods

\footnotetext{
${ }^{43}$ Finnis, Natural Law and Natural Rights, 11.

${ }^{44}$ Ibid.

${ }^{45}$ Ibid.

${ }^{46}$ Ibid.

${ }^{47}$ It should be noted that viewpoint and purposes are not necessarily aligned, in the sense that they can independently influence the development of a central case. For example, Finnis' central case of law is different from Hart's central case of law, since the two theorists adopt different viewpoints; nonetheless, both theories of law have been developed in light of certain theoretical purposes that legal scholars associate with the discipline of analytical jurisprudence. On the other hand, the existence of different (theoretical) purposes explains why Finnis' and Hart's theory of law can be grouped together as offering peripheral cases of law, when considered from the perspective of an historian, or of a natural scientist.
} 
(and their open-ended realisations). In relation to this point, Finnis considers whether the existent practices which directly oppose the basic goods may generate a challenge for his methodology. Considering that, for example, the reasonable person would never deliberately choose to establish a slavery system of labour, or to run an extermination camp, how can a theorist develop central cases of these phenomena? How can the theorist distance their perspective from that of the people who deliberately take part in institutions and/or ideologies that directly oppose one (or more than one) basic goods $?^{48}$ Finnis' answer to these question is based upon a robust account of practical reasonableness, according to which 'such acts and practices earn a place in social theory only by their opposition (harm, threat) to and/or parasitism on those goods and requirements of practical reasonableness that they harm and flout, or imitate with unreasonable deviations and restrictions'. ${ }^{49}$ Finnis' account of practical reasonableness and his understanding of the basic goods - which, together, characterise his version of the central case method - inform the methodology that support the investigation carried out by Ekins in The Nature of Legislative Intent.

\section{Three issues about the nature of the legislature}

Ekins' investigation of the nature of the legislature focuses on the central case of the legislature - i.e. the well-formed legislature chosen and maintained by practically reasonable persons. The first part of this article has illustrated Finnis' methodology, with a view to clarifying Ekins' central case method. The theory of legislative intent developed by Ekins, together with the textual evidence considered at the beginning of Section 1, show that, at a general level, there are no significant differences between Ekins' and Finnis' view on the sound formation of general concepts for descriptive social science. One may wonder, however, whether this is also true at a particular level, given that Finnis applies the central case method to explain the nature of law, whereas Ekins applies it to explain the nature of the legislature. This difference provides the context for the second part of the article, where I will discuss three main aspects of Ekins' understanding of the nature of the legislature, focusing in particular on: the relationship between the well-formed legislature and the idea of a good

\footnotetext{
${ }^{48}$ See Finnis, Natural Law and Natural Rights, 430: 'From the viewpoint of those who choose such acts or ways of life or institutions or ideologies, efficacy and sustainability in service of their individual purposes, whatever the cost to the victims, is doubtless a primary criterion of centrality'. For a discussion of this passage, see: Timothy Endicott, 'The Irony of Law', in John Keown and Robert P. George (eds.), Reason, Morality, and Law: The Philosophy of John Finnis (Oxford: Oxford University Press, 2013), 330.

${ }^{49}$ Finnis, Natural Law and Natural Rights, 430.
} 
polity ( $\$ 2.1)$; the notion that the well-formed legislature acts for good reasons $(\S 2.2)$; and the relationship between well-formed legislature and the central case of law (§2.3).

\subsection{The relationship between the well-formed legislature and the idea of a good polity}

Ekins' account of the nature of the legislature appears to establish a conceptual relation between the well-formed legislature and the idea of a good polity: 'The legislature is the preeminent law making body in any good polity, as well as the central political institution, the deliberation and action of which is the focus of democratic political life' ${ }^{50}$ Does this proposition entail the notion that it is not possible to have a good polity without a legislature? Here Ekins seems to suggest that there is indeed a connection between the central case of the legislature and the central case of polity. This conceptual connection reveals three dimensions of the nature of the legislature - in relation to a good polity, the well-formed legislature is a democratic, central, and representative institution. The claim that the deliberation and action of the legislature is the focus of democratic life suggests that the well-formed legislature is democratic in nature. Ekins argues that the legislature is well-suited to be the central lawmaking body of a polity because of its openness and its freedom. ${ }^{51} \mathrm{He}$ also argues that, given the role of parties and elections in the political life of modern polities, the well-formed legislature should be conceived of as representing the entire community. ${ }^{52}$

Each dimension of the well-formed legislature can be problematised. First, one may ask whether democracy is, or should be, an element of both the well-formed legislature and the good polity; and how the democratic life of the good polity does or should shape the role of the legislature, qua legal and political institution (considering that this two-fold role might generate internal tensions). ${ }^{53}$ Secondly, provided that the leading role played by the legislature in making law for the polity depends upon its openness and freedom, it is possible to ask, especially in light of the idea of a constitutional government, whether the legislature's openness and freedom should be somehow limited - in order to maintain the legislature as the

\footnotetext{
${ }^{50}$ Ekins, The Nature of Legislative Intent, 9.

${ }^{51}$ Ibid, 11: '...the legislature's openness in principle to all that is relevant, and its freedom to act deliberately and comprehensively, make it well suited to be the polity's central or leading law making body'.

${ }^{52}$ Ibid, 150: 'In the modern polity, legislators very often form parties and contest elections in these parties. The legislator thus represents a constituency that elected him, forms part of an institution (the legislature) that represents the entire community, and belongs to a party that coordinates the actions of its members by reference to a shared manifesto and leadership'.

${ }^{53}$ On the legislature as a legal and a political institution, see, infra, §2.3.1.
} 
central and leading law-making institution of the polity. ${ }^{54}$ Thirdly, it would be interesting to examine how the formation of political parties and the link between each legislator and a particular constituency - considering the different ways in which these requirements are implemented in the political practice of different democratic regimes - may be not only necessary, but also sufficient conditions for the well-formed legislature to represent the entire community (including the members of the community who are not part of the electorate).

In the next section I will discuss other potential issues and/or lines of enquiry associated with the relationship between the central case of the legislature and the central case of a polity, in light of the three elements of the central case method illustrated in Section 1.2 - i.e. the four orders of knowledge; the priority of the 'Why-question'; and the relationship between central and peripheral cases.

\subsubsection{The central case method and the relationship between legislature and polity}

Both the legislature and the polity are human groups that can be identified in light of their purpose(s). When considering the relationship between the central case of the legislature and the central case of a polity, the most revealing comparison between these two human groups relates to the fourth order of their unity. More precisely, in order to explain the nature of the legislature, it is helpful to consider the purpose(s) of the well-formed legislature vis-à-vis the purpose(s) of the good polity. These two purposes (or sets of purposes) partially overlap and this overlap is captured by the idea of the common good of the political community. For those interested in engaging with Ekins' understanding of the legislature, this overlap is significant, because it shows that, on the one hand, the well-formed legislature is intrinsically connected with the (good) polity; and, on the other hand, the well-formed legislature has its own common good, qua human group. This is a point that is worthy of further exploration.

As explained in Section 1.2, the fourth order of knowledge does not exclude the other three orders; in fact, to a certain extent, the fourth order presupposes and includes the other orders. So, it would also be interesting to explore the nature of the well-formed legislature in relation

\footnotetext{
${ }^{54}$ While limitations on the openness of the legislature can be seen as limits on the content of legislation, limitations on the freedom of the legislature can be seen as limits on the manner and form of the legislative process.
} 
to its physical unity, the unity provided by the type of reasoning and language used by the legislature, as well as the unity of the techniques that are proper to the legislature. ${ }^{55}$

The second element of the central case method - i.e. the gnoseological priority ascribed to the 'Why-question' - suggests another way in which the relationship between the well-formed legislature and the good polity can be analysed. In this context, the simplest formulation of the 'Why-question' is the following: Why should we have a legislature? Ekins' theory suggests that this question can be answered only in the context of an understanding of the purpose of the polity - viz. Why should we, in our polity, have a legislature? Now, the way in which one answers this last question depends (at least, partially) on the specific features of 'our' polity. Hence, it may be argued that, when exploring the nature of the legislature, the what-questions about the polity should have (relative) priority over the why-questions about the polity. For example, the representative character recognised by Ekins as part of the nature of the legislature is particularly significant in relation to a large polity, where direct democracy is not feasible and/or desirable. So, it seems to me that the claim that the legislature is the pre-eminent law-making body in any good polity should be unpacked - if not qualified - in relation to the structural characteristics of the (good) polity one has in mind.

Finally, the relationship between the idea of the well-formed legislature and idea of the good polity can be analysed in light of the relationship between the central case and the peripheral cases of a social phenomenon. In particular, it would be interesting to consider whether the connection between these two ideas remains stable when one's focus shifts from the central to the peripheral cases. For example, one may ask to what extent a deficient legislature can co-exist with a good polity, or vice versa. In this context, it seems to me that the following problem - that I would call 'the gradient problem' - is worth of special attention. The connection between the legislature and the polity does not appear to be problematic when one considers these two human groups in their central case, or in the worst borderline case. The gradient problem concerns the situations that lie in between these extremes - that is to say, how the proximity of the legislature of a given polity to the central case of the legislature is affected by the proximity of that polity to the central case of a polity. More precisely, given a legislature $\mathrm{L}$ in the polity $\mathrm{P}$, the gradient problem invites one to ask whether the nature of $\mathrm{L}$ should be conceived of as a direct function of the nature of $\mathrm{P}$. This question is significant not

\footnotetext{
55 This might also provide occasion for a fruitful collaboration between legal and political theory and other (theoretical and/or experimental) disciplines.
} 
only when one studies particular instances of the legislature, but also when one tries to understand the well-formed legislature. Therefore, it seems to me that the kind of investigation carried out in The Nature of Legislative Intent should not ignore the gradient problem. Also, considering that, despite its (alleged) centrality, the legislature is not the only legal and/or political institution of the polity, it may well be possible that in order to appreciate and explain the relationship between the well-formed legislature and good polity it is necessary to consider how the existence and the role of other legal and political institution may affect that relationship.

\subsection{Legislation and good reasons}

A second aspect of Ekins' understanding of the nature of the legislature focuses on the reasons that underpin the acts of the legislature. For the purposes of Ekins' project, the identification of these reasons is important because it is in light of these reasons that one can explain the distinctive capacities of the legislature, which in turn allow one to explain the actions and the shape of the well-formed legislature. ${ }^{56}$ In this context, Ekins argues that the rationale for having a legislature lies in the legislature's capacity to change the law 'for good reasons'. This means that in order to properly understand the nature of the legislature one must be able to distinguish between 'good' and 'bad' reasons to change the law (and/or introducing a new law in relation to situations that should be regulated, even though they are not regulated by the existing legal order). This is an important step in Ekins' argument, together with the acknowledgment that it would be unreasonable to change the law 'in general', without an appeal to reasons. Indeed, Ekins argues that 'rationality' requires one to change the law for what one takes to be good reasons. ${ }^{57}$ This suggests that the nature of the legislature - or, at least, one aspect of its nature - can be illuminated by the (good) reasons that underpin the law-making process; and that these are the reasons that the legislators take to be good reasons.

The gist of this argument follows from the central case method and is convincing. However, this argument seems to intrinsically link the reasons to legislate, viz. the reasons to change

\footnotetext{
${ }^{56}$ Ekins, The Nature of Legislative Intent, 9: 'I aim to perceive and explain the shape of the well-formed legislature and its action, which is the exercise of its distinctive capacities'.

${ }^{57}$ Ibid, 113: 'It is not rational to intend just to change the law in general, in the same way that it is not rational for an author to intend to convey some meaning in general. Rational law making is action to change the law in specific ways for (what the legislature takes to be) good reasons'.
} 
the law in a particular way, with the reasons that underpin the decision to establish and maintain the legislature. Indeed, Ekins searches for '... what reasons, if any, there are to establish the legislature, serve as a legislator, and follow legislation as a citizen'. ${ }^{58}$ The context of this proposition suggests that the reasons to change the existing law and/or make new laws (i.e. the reasons to serve as a legislator) can be grouped together with - if they are not identical to - the reasons to establish a law-making institution and to follow the laws made by that institution. Now, it seems to me that these three types of reasons should be distinguished and, possibly, kept separate; not only because they relate to different actors, but also because there may well be internal tensions between them.

A first potential tension may arise between the reasons to follow the law and the reasons to make the law. Think, for example, of an unjust law in the context of an otherwise just legal order: citizens may have good reasons to follow that unjust law, but the reasons adopted by the legislators to introduce that law cannot be good reasons - by definition, considering that we know that the result of the legislative process is unjust. Another potential tension is between the reasons to establish the legislature and the reasons to legislate. Consider, for instance, the existence of an entrenched constitutional rule about the legislative process: while this rule is consistent with - and, indeed, part of - the establishment of the legislature, the rule is in tension with the law-making process (given that, by definition, it constrains that process, formally and/or substantively). Therefore, the existence of this rule would generate a tension between the reasons that support the law-making process and the reasons that support the establishment of the legislature - considering that the rationale for having a similar entrenched rule can be seen as part of the reasons to establish the legislature.

In the next sub-section, I will refer to the three elements of the central case method illustrated in Section 1.2 to identify other potential issues and/or lines of further enquiry associated with the notion that our understanding of the well-formed legislature depends upon our understanding of the reasons that support the actions of the legislature as the central institution of any good polity.

\footnotetext{
${ }^{58}$ Ekins, The Nature of Legislative Intent, 118.
} 


\subsubsection{The central case method and the good reasons to legislate}

According to Ekins, "for the legislature to act well it must respond to good reasons for changing the law by choosing to introduce certain propositions into the law'. ${ }^{59}$ The legislature is a group that can act; and its actions (which produce new laws) can respond to reasons. A sound understanding of the nature of the legislature requires one to reflect upon the joint action that creates a unifying relationship between the legislators - i.e. the individual members of the human group that we call 'the legislature'. Indeed, Ekins affirms that 'the well-formed legislature is a single, rational agent, which there is good reason to presume acts for good reasons rather than for any reason or no reason'. ${ }^{60}$ Thinking of the legislature as a single agent helps one to focus on the most important unifying relationship that characterises the legislature (i.e. the fourth order of knowledge). However, acknowledging the explanatory power of the fourth order should not obfuscate the importance of the other three orders. When Ekins correctly explains that the legislature changes the existing law and/or make new law by introducing certain propositions into the legal order, he touches upon a characteristic feature of the legislature. The law-making process, whether motivated by good reasons or not, brings about a result of a particular type: legal provisions and the legal norms associated with them. A comprehensive exploration of the nature of the legislature should illuminate not only the reasons that underpin the law-making process (together with the potentially different reasons that underpin the decisions to establish, maintain and/or follow the legislature), but also the reasons that cause the result of the legislative process to have a particular form - i.e. general norms. Paying attention to this dimension of the relationship between (good) reasons and legislation - understood as an activity, but also as the result of this activity - would push the exploration of the nature of the legislature in two directions. First, it would lead one to investigate the links between all the four unifying relationships that allow one to recognise the legislature as a group. Secondly, it would lead one to consider the purpose(s) of the lawmaking process in relation to the purpose(s) of the legislation, understood as a set of general legal norms.

The notion that law-making is a purposive enterprise can also be problematised independently. According to Ekins, the actions of well-formed legislature - i.e. the

\footnotetext{
${ }^{59}$ Ekins, The Nature of Legislative Intent, 218.

${ }^{60} \mathrm{Ibid}, 256$.
} 
formulation, evaluation, revisions, and enactment of legislation - respond to 'reasons that bear on the common good'. ${ }^{61}$ To what extent the reasons that support the actions of the wellformed legislature in a well-formed polity should articulate the common good of that polity? Alternatively, should the reasons that are linked to the existence and the activities of the wellformed legislature in a well-formed polity be informed by an understanding, and an articulation, of the common good of that polity?

To conclude this section, a quick comment on the order of explanation - suggested by gnoseological priority of the 'Why-question' over the 'What-question'. Ekins argues that in order to understand the nature of the legislature one should begin by considering the objects of the legislature and, subsequently, its acts, which depend upon those objects; for the acts of the legislature illuminate its capacities, which are the key to understanding the dynamic reality of the legislature. ${ }^{62}$ This order of explanation gives priority to the question: why should the legislature change the law (or make new law)? This 'Why-question' helps one to understand the nature of the law-making process, by focusing on the objects of this process. It seems to me that in order to illuminate the nature of the legislature, this particular 'Whyquestion' should not be considered in isolation; but rather in connection with other 'Whyquestions': Why should we have a legislature in the first place?; Why should our legislature be maintained?; Why should we/they (as legislators) legislate?; Why should we/they (as citizens) follow the legislation?

\subsection{The well-formed legislature and the central case of law}

This last section considers the relationship between the well-formed legislature and the central case of law, as Ekins argues that the well-formed legislature - seen as an institution with the capacity to change the law through deliberation - is fundamental to the central case of law. ${ }^{63}$ Ekins' understanding of the relationship between the concept of a legislature and the concept of law is different from the way in which legal positivists - in particular, Hart and Raz - understand this relationship. On this point, Ekins explicitly disagrees Raz's view that

\footnotetext{
${ }^{61}$ Ekins, The Nature of Legislative Intent, 124.

${ }^{62}$ Ibid, 118: 'the key to understanding the nature of a dynamic reality is to understand its capacities, which one understands by understanding its acts, which in turn one understands by understanding its objects-that for which it acts'.

${ }^{63}$ Ekins, The Nature of Legislative Intent, 121.
} 
norm-creating institutions (e.g. a legislature) are not a necessary element of a legal system; whereas norm-applying institutions, viz. courts, are. ${ }^{64}$

Let me briefly recall Raz's view. Raz thinks 'that the key to the systematic nature of law lies with the functioning of the law-applying institutions'. ${ }^{65}$ According to Raz, normative institutions are key to determining if a given normative system is in force, and therefore exists; and which norms belong to that system (because of the role played by those institutions in the criterion of identity of the system). Raz criticises the idea that legal systems, as well as similar normative systems, are 'systems of a common origin'. In some theories - e.g. in Hobbes, or Austin - this idea is expressed through the notion that a legal system is the set of all the norms issued by one (sovereign) legislator. In other theories - e.g. in Kelsen - this idea is expressed through the notion that a legal system is the set of all the norms deriving their validity from one (single) norm. In both cases, legal systems are conceived of as having a common origin. According to Raz, the idea that legal systems are systems of a common origin is problematic because it cannot explain two main features of legal systems, qua complex institutionalised systems: their unity and their existence. ${ }^{66}$ Raz offers two arguments against the idea that legal systems are systems of a common origin. First, he argues that it is possible for a legal system to have multiple legislators, each enjoying independent authority; and, secondly, that the key to establishing that a legal system exists lies in the fact that the norms of the system are practised by some institutions of the system. In the context of this second argument, Raz affirms that the fact that the norms of the system are practised cannot be ascertained in relation to norm-creating institutions. ${ }^{67}$ Instead, to determine whether a legal system is in force, and therefore exists, one should rely upon the practice of the law-applying institutions.

The disagreement between Ekins and Raz is due to methodological and theoretical reasons. There is a methodological tension in the way in which Ekins and Raz develop their concept of law. Ekins sees this concept as linked to the central case of law; whereas Raz is interested

\footnotetext{
${ }^{64} \mathrm{Ibid}$

${ }^{65}$ Joseph Raz, Practical Reason and Norms (Oxford: Oxford University Press, 1999), 129.

${ }^{66}$ For Raz, only the simplest forms of institutionalised (legal) systems can be explained in light of the idea that legal systems are systems of a common origin.

${ }^{67}$ See Raz, Practical Reason and Norms 131: '[Norm-creating institutions] can at best practise those norms addressed to them and there is no reason to regard a system as in force simply because it is acceptable to those who lay down its rules. That it is in force must depend somehow on what happens to those who are the norm subjects of the norms of the system.'
} 
in the necessary and sufficient conditions that must be satisfied for a set of norms to be a legal system. In doing so, Raz develops his project within the Hartian methodological paradigm. ${ }^{68}$ On the other hand, Ekins' research is informed by Finnis' methodology (which develops, but also challenges, Hart's methodology). ${ }^{69}$ Because of their methodological background, it is not surprising to find Ekins and Raz disagreeing on the role played by the legislature in the development of the concept of law. In resisting Raz's argument, Ekins suggests that it is possible to imagine a community with a set of legal norms, but without officials to change (and/or apply) those norms: this community has a form of law, but their law lacks a number of elements of the central case of law, including the official modification (and/or the impartial application) of the legal norms of the community. For Ekins, Raz's concept of a legal system captures a legal reality that is only analogous to the central case of law. This is because a community without a legislature is not able to respond to the need for legal change: therefore, the law of such a community lacks one of the distinctive features of a worthwhile legal order - 'the capacity for a community to act to modify the rules that structure its social life' ${ }^{70}$ In light of this, it seems to me that Ekins' understanding of the well-formed legislature - seen as a community's central norm-creating institution - depends upon a general theory of law as well as a general theory of normative systems (considering that legal norms are a sub-set of the norms that structure the social life of the community).

\subsubsection{The central case method and the relationship between the well-formed legislature and the central case of law}

It is helpful to analyse the relationship between the central case of the legislature and the central case of law through the prism of the four order of knowledge illustrated in Section 1.2 , as this allows one to identify an asymmetry in that relationship. Once again, the fourth unifying relationship - i.e. the unity provided by joint action - is particularly significant. While the nature of the legislature can be explained in light of the idea of a group united by the joint action of its individual members (i.e. the legislators), a proper account of the nature of law appears to require more than this. After all, the reality of the legislature is less complex than the reality of law, and the former is commonly seen as included in (or as a part of) the latter. The asymmetry in the relationship between the idea of the well-formed

\footnotetext{
${ }^{68}$ See, e.g.: H.L.A. Hart, The Concept of Law, 116.

${ }^{69}$ See, supra, §1.1.

${ }^{70}$ Ekins, The Nature of Legislative Intent, 121.
} 
legislature and the idea of law emerges when one focuses on the building blocks of these two ideas. The idea of the legislature can be unpacked in the following notions: the norm(s) conferring power to an assembly to legislate; the assembly called 'the legislature'; the legislative process through which that assembly acts; and, finally, the result of the legislative process (i.e. laws). In relation to the idea of law, it is possible to identify the following elements: power-conferring rules, legal institutions, law-related activities (viz. the making, the application and the enforcement of laws), duty-imposing rules (both general and individual), legal principles and doctrines. When exploring the nature of law, thinking about (the central case of) the legislature is conducive to a reflection on the role that legal institutions, and the process through which laws are created and modified, should play in legal theory. Yet, for the purposes of a general theory of law - understood as an explanation of the central case of law - the legislature, qua law-making institution, should be studied together with other key legal institutions; and the theoretical importance of legislation (as a process and/or the result of this process) should be appreciated in all its dimensions, including its constitutional regulation, its interpretation, its enforcement, and its reception by the members of the polity.

This last point also emerges in relation to the gnoseological importance of the "Whyquestion'. By focusing on this question, Ekins identifies an important feature of the wellformed legislature: it is an assembly set up to legislate for the community. For Ekins, the purpose of legislative action is not simply to change the community's set of legal norms, but to change them for the common good of the community. This means that an appeal to the notion of the common good is necessary to understand the nature of the legislature; but this notion is also crucial to identify and understand those human groups that we call 'political communities', or 'polities'. Here, it is worth considering how the legislature, and the law, of a given polity can help that polity realise (in an open-ended way) its common good. In relation to Ekins' theory, it should be considered how the explanation of the well-formed legislature is affected by the fact that legislators only have a partial appreciation of the common good of their polity, either directly, or indirectly - that is to say, mediated through the partial understanding of the common good proper to the law of the polity (assuming that the common good of the polity does not equate to the common good of the polity's legal order). ${ }^{71}$

\footnotetext{
${ }^{71}$ In addressing this question, one may argue that, despite the fact that the legislators' competence to care for the common good of their community is limited, in order to legislate properly they must not only understand, but also commit themselves to promoting, the common good of their community. It seems to me that, even
} 
In conclusion, I would like to draw a parallel between the legislature-law relationship and the legislature-polity relationship. In Section 2.2.1, I suggested that establishing that the central case of the legislature is connected with the central case of the polity gives rise to a problem that I called 'the gradient problem'. This is because, once a connection between the central case of the legislature and the idea of the polity is established, it follows that the transformations of this idea along the spectrum of central and peripheral cases of polity may affect our description of the central case of the legislature; and, therefore, our understanding of the nature of the legislature. The gradient problem also emerges in the context of the relationship between the well-formed legislature and the central case of law. Connecting these two ideas means that the transformations of one social entity along the spectrum of its central and peripheral cases may affect our description of the central case of the other social entity - and, therefore, our understanding of the nature of the legislature and/or law.

An appreciation of the 'gradient problem' may suggest avenues for further research on the relationship between the idea of the legislature and the idea of law. Furthermore, the legislature-law relationship and the legislature-polity relationship may be combined, as they appear to be part of the same social reality: the legislature is a part of the law, which is, in turn, part of the polity. This combination suggests another possible line of enquiry. Ekins argues that the legislature is central to both the legal and the political life of the polity. Indeed, the legislature is a central legal and political institution. However, it might be useful to distinguish the 'Legislature (qua legal institution) - Law - Polity' connection from the 'Legislature (qua political institution) - State - Polity' connection. This distinction does not have to amount to a separation, as the value of the distinction lies in the clarity that it would bring to the exploration of different aspects of the life of the legislature. In line with the central case method employed in The Nature of Legislative Intent, a more nuanced analysis of the life of the legislature would improve our description of the well-formed legislature, and, therefore, our understanding of the nature of the legislature.

conceding this point, there is an important difference between the way in which (reasonable) members of a political community understand, and realise, the common good of their community and the institutionally limited understanding, and realisation, of the common good proper to the (reasonable) members of the legislature. Therefore, my view is that a theory of the well-formed legislature should acknowledge and explain this difference. 